\title{
Pulsed ultrasound associated with gold nanoparticle gel reduces oxidative stress parameters and expression of pro-inflammatory molecules in an animal model of muscle injury
}

Eduardo G Victor', Paulo CL Silveira², Jonathann C Possato', Guilherme L da Rosa², Uillian B Munari', Claudio T de Souza ${ }^{2}$, Ricardo A Pinho ${ }^{2}$, Luciano da Silva ${ }^{1}$, Emilio L Streck ${ }^{3}$ and Marcos MS Paula ${ }^{1 *}$

\begin{abstract}
Background: Nanogold has been investigated in a wide variety of biomedical applications because of the antiinflammatory properties. The purpose of this study was to evaluate the effects of TPU (Therapeutic Pulsed Ultrasound) with gold nanoparticles (GNP) on oxidative stress parameters and the expression of pro-inflammatory molecules after traumatic muscle injury.

Materials and methods: Animals were divided in nine groups: sham (uninjured muscle); muscle injury without treatment; muscle injury + DMSO; muscle injury + GNP; muscle injury + DMSO + GNP; muscle injury + TPU; muscle injury + TPU + DMSO; muscle injury + TPU + GNP; muscle injury + TPU + DMSO + GNP. The ROS production was determined by concentration of superoxide anion, modulation of antioxidant defenses was determined by the activity of superoxide dismutase, catalase and glutathione peroxidase enzymes, oxidative damage determined by

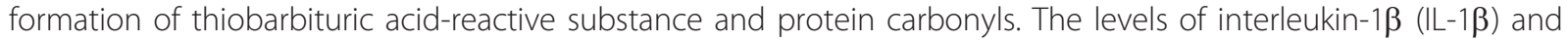
tumor necrosis factor- $\alpha$ (TNF- $\alpha$ ) were measured as inflammatory parameters.

Results: Compared to muscle injury without treatment group, the muscle injury + TPU + DMSO + GNP gel group promoted a significant decrease in superoxide anion production and lipid peroxidation levels $(p<0.050)$. It also showed a significant decrease in TNF- $\alpha$ and IL-1 $\beta$ levels $(p<0.050)$ when compared to muscle injury without treatment group.
\end{abstract}

Conclusions: Our results suggest that TPU + DMSO + GNP gel presents beneficial effects on the muscular healing process, inducing a reduction in the production of ROS and also the expression of pro-inflammatory molecules.

Keywords: gold nanoparticles, oxidative stress, therapeutic pulsed ultrasound, anti-inflammatory, reactive oxidative species

\section{Background}

Muscle contusion usually results from a direct blunt impact and is frequently associated with contact sports. Muscle contusion results from microscopic muscle fiber and capillary disruption with resultant microhemorrhage dissecting between the torn fibers and the remaining

\footnotetext{
* Correspondence: bocaocao@gmail.com

'Laboratory of Synthesis of Multifunctional Complexes, UNESC Av. Universitária, 1105 - Bairro Universitário Phone: + 554834312773 88806-000 - Criciúma - SC, Brazil

Full list of author information is available at the end of the article
}

viable muscle fibers [1]. Muscle injury typically initiates a rapid and sequential invasion of muscle by inflammatory cell populations that can persist for days to weeks, while muscle repair, regeneration, and growth occur [2].

Many studies have demonstrated that muscle injury induces an increased generation of Reactive Oxidative Species (ROS), which alters intracellular oxidant-antioxidant balance in favour of the former and can result in oxidative damage of traumatized muscle when the production of ROS overwhelms the antioxidant defense systems [3]. Oxidative stress has an important role in

\section{Ciomed Central}

(c) 2012 Victor et al; licensee BioMed Central Ltd. This is an Open Access article distributed under the terms of the Creative Commons Attribution License (http://creativecommons.org/licenses/by/2.0), which permits unrestricted use, distribution, and reproduction in any medium, provided the original work is properly cited. 
muscle damage and may be associated with cellular membrane damage via disruption of $\mathrm{Ca}^{2+}$ ion channels leading to imbalance in $\mathrm{Ca}^{2+}$ homeostasis [4]. Multiple potential sites for ROS generation in skeletal muscle have been identified including mitochondria, NADPH oxidase enzymes, phospholipase A2-dependent processes, and xanthine oxidase [5].

The cytokines further promote the migration, proliferation and survival of various cell types at the injury site, whereas the inflammatory cells are responsible for the phagocytosis of cell debris [6]. Macrophage-released cytokines, including leukemia inhibitory factor, IL-1 and IL-6, have emerged as part of the muscle repair mechanism. In addition, it is increasingly clear that tumor necrosis factor- $\alpha$ (TNF- $\alpha$ ), a major pro-inflammatory cytokine produced by activated macrophages, has an important role in muscle repair [7].

Recent studies concluded that some physical methods including therapeutic ultrasound treatments accelerate and facilitate wound healing, improve scar quality, and have beneficial effects on muscle and tendon healing [8]. Therapeutic ultrasound is used to promote healing in a variety of situations, such as in reducing edema, accelerating tissue repair, decreasing pain, and modifying the formation of scar tissue. Furthermore, ultrasound may enhance penetration of anti-inflammatory agents applied to the skin in a technique called phonophoresis [9]. Phonophoresis has been used clinically as a physical therapy for musculoskeletal lesions. Therefore, antiinflammatory drugs and local anesthetics have been frequently administered via this route [10].

Nanogold (also called gold nanoparticle or colloidal gold) has been actively investigated in a wide variety of biomedical applications due to its biocompatibility and ease of conjugation to biomolecules [11,12]. According to Tsai (2007) [13], nanogold has anti-inflammatory effect by decreasing pro-inflammatory cytokines and macrophage infiltration in a model of arthritis.

Due to anti-inflammatory properties of therapeutic pulsed ultrasound (TPU) and the growing interest in the research of gold nanoparticles, the present study aims at linking these two treatments (phonophoresis), evaluating their effects on the cytokines TNF- $\alpha$ and IL- $1 \beta$ and oxidative stress parameters after traumatic muscle injury.

\section{Materials and methods}

\section{Synthesis of Gold Nanoparticles}

Gold nanoparticles were prepared as previously described by Turkevich et al. (1951) [14]. Briefly, an aqueous solution of sodium citrate was added to a hydrogen tetrachloroaurate $\left(\mathrm{HAuCl}_{4}\right)$ solution previously heated to $90^{\circ} \mathrm{C}$. The system was maintained under reflux with magnetic stirring for $20 \mathrm{~min}$. Gold nanoparticles were characterized by UV-vis and TEM (transmission electron microscopy). The electron spectrum shows an absorption peak at approximately $520 \mathrm{~nm}$, attributed to the surface plasmon resonance absorption. TEM image of nanoparticles revealed the presence of nearly spherical particles with mean particles diameter of $25 \mathrm{~nm}$.

\section{Animals}

Male Wistar rats (250-300 g) obtained from the Central Animal House of the Universidade do Extremo Sul Catarinense (UNESC), Santa Catarina, Brazil, were caged in groups of six, offered commercial rat chow and water ad libitum, and maintained on a $12 \mathrm{~h}$ light $/ 12 \mathrm{~h}$ dark cycle. The animals were randomly divided into nine groups $(\mathrm{n}=6)$ : sham (uninjured muscle); muscle injury without treatment; muscle injury and treatment with DMSO gel $(15 \mathrm{mg} / \mathrm{kg})$; muscle injury and treatment with GNP gel $(27 \mu \mathrm{g})$; muscle injury and treatment with DMSO + GNP gel; muscle injury and TPU $\left(0.8 \mathrm{~W} / \mathrm{cm}^{2}\right)+$ saline gel $(0.9 \%)$; muscle injury and TPU $\left(0.8 \mathrm{~W} / \mathrm{cm}^{2}\right)+$ DMSO gel $(15 \mathrm{mg} / \mathrm{kg}) ;$ muscle injury and TPU $\left(0.8 \mathrm{~W} / \mathrm{cm}^{2}\right)+$ GNP gel $(27 \mu \mathrm{g})$; muscle injury and TPU $\left(0.8 \mathrm{~W} / \mathrm{cm}^{2}\right)+$ DMSO + GNP gel. All studies were performed in accordance with guidelines of National Institutes of Health and with the approval of the Ethics Committee of the Universidade do Extremo Sul Catarinense, Santa Catarina, Brazil.

\section{Muscle injury model}

The muscle trauma model used has been described by Rizzi et al. (2007) [15]. Animals were anesthetized with intraperitoneal injection of ketamine $(70 \mathrm{mg} / \mathrm{kg})$ and xylazine $(15 \mathrm{mg} / \mathrm{kg})$. Gastrocnemius injury was induced by a single-impact blunt trauma in a press developed by the Centro Industrial de Equipamentos de Ensino e Pesquisa (CIDEP, Porto Alegre, RS, Brazil). Briefly, injury was produced by a metal mass $(0.459 \mathrm{~kg})$ falling through a metal guide from a height of $18 \mathrm{~cm}$. The impact kinetic energy delivered was 0.811 Joules. Sham rats were also anesthetized to ensure standardization, but without muscle trauma.

\section{Treatment}

Treatment with TPU(Imbramed, Amparo, São Paulo, Brazil, 6 min duration, frequency of $1.0 \mathrm{MHz}$, intensity of $0.8 \mathrm{~W} / \mathrm{cm}^{2}$, effective radiating area [ERA] $1 \mathrm{~cm}^{2}, 50 \%$ duty cycle of 1:2 [ $5 \mathrm{~ms}$ on, $5 \mathrm{~ms}$ off] and focused geometry of the ultrasound beam) was used 2, 12, 24, 48, $72,96,120,144$, and $168 \mathrm{~h}$ after muscle trauma, adapted from Silveira et al. (2010) [16]. The ultrasound treated area had approximately $2 \mathrm{~cm}^{2}$, according to Rizzi et al. (2007) [15]. The movement of the beam was circular, according to Saliba et al. (2007) [17]. The groups with muscle injury and treatment with DMSO gel, GNP gel, 
and DMSO + GNP gel also were exposed to treatment for $6 \mathrm{~min}$.

\section{Sacrifice protocol}

Two hours after the last application, animals were killed by decapitation. The injured region of the gastrocnemius muscle was surgically removed and immediately processed, aliquoted and stored at $-70^{\circ} \mathrm{C}$ for subsequent analysis.

\section{Sample preparation}

The injured region of the gastrocnemius was homogenized in the buffer used for each technique. The homogenates were centrifuged at $1000 \mathrm{~g}$ for $10 \mathrm{~min}$ at $4^{\circ} \mathrm{C}$ and the supernatants kept at $-70^{\circ} \mathrm{C}$ until used in the experiments. The maximal period between homogenate preparation and biochemical analysis was always less than 5 days.

\section{Biochemical Assays \\ Measurement of mitochondrial superoxide generation}

Submitochondrial particles were isolated by differential centrifugation, as previously described by Poderoso et al. (1996) [18]. Superoxide anion production was estimated by measuring adrenaline oxidation in a buffer containing submitochondrial particles, succinate (as electron transfer chain initiator) and catalase. Results were expressed in $\mathrm{nmol} / \mathrm{min} / \mathrm{mg}$ protein.

\section{Lipid peroxidation}

The formation of thiobarbituric acid-reactive substances (TBARS) during a TBA-heating reaction was used as an index of lipid peroxidation, as previously described by Draper and Hadley (1990) [19]. Briefly, the samples were mixed with $1 \mathrm{~mL}$ of $10 \%$ trichloroacetic acid and 1 $\mathrm{mL}$ of $0.67 \%$ thiobarbituric acid. Subsequently, they were heated in a boiling water bath for $30 \mathrm{~min}$. TBARS level was determined through absorbance at $532 \mathrm{~nm}$ using 1,1,3,3-tetramethoxypropane as an external standard. Results were expressed as TBARS level $(\mathrm{nmol} / \mathrm{mg}$ protein).

\section{Protein carbonyls}

Oxidative damage to proteins was measured by determining carbonyl groups based on the reaction with dinitrophenylhydrazine (DNPH) [20]. Proteins were precipitated by adding $20 \%$ trichloroacetic acid and reacted with DNPH. The samples were then redissolved in $6 \mathrm{M}$ guanidine hydrochloride and carbonyl contents were determined through absorbance at $370 \mathrm{~nm}$ using a molar absorption coefficient of $22.000 \mathrm{M}^{-1}$ and total protein were determined by absorbance of $270 \mathrm{~nm}$ in the same sample. Results were expressed as carbonyl level (nmol/mg protein).

\section{Superoxide dismutase (SOD) activity}

SOD activity was assayed by measuring the inhibition of adrenaline auto-oxidation as absorbance at 480 $\mathrm{nm}$, as previously described Bannister and Calabrese (1987) [21]. Results were expressed in U SOD/mg protein.

\section{Glutathione peroxidase (GPX) assay}

GPx activity was measured by using tert-butyl-hydroperoxide as substrate [22]. Enzyme activity was measured by monitoring the rate of disappearance of NADPH at $340 \mathrm{~nm}$ in $50 \mathrm{mM}$ potassium phosphate buffer, $\mathrm{pH}$ 7.0, containing $1.0 \mathrm{mM}$ EDTA, $2.0 \mathrm{mM}$ glutathione (GSH), $0.2 \mathrm{U} / \mathrm{mL}$ GSH reductase, $1.0 \mathrm{mM}$ azide, $0.2 \mathrm{mM}$ tertbutyl-hydroperoxide, $0.2 \mathrm{mM} \mathrm{NADPH}$, and supernatant containing 0.2-0.3 $\mathrm{mg}$ protein $/ \mathrm{mL}$.

GPx activity was expressed as nmol of NADPH oxidized per minute per $\mathrm{mg}$ of protein, using an extinction coefficient of $6.22 \times 10^{6}$ for NADPH.

\section{Catalase (CAT) activity}

Catalase activity was measured by the rate of decrease in hydrogen peroxide absorbance at $\lambda_{\max }=240 \mathrm{~nm}$ [23], and results were expressed in U CAT/mg protein.

\section{Protein analysis by immunoblotting}

The injured region of the gastrocnemius muscle was surgically removed and homogenized immediately in extraction buffer (1\% Triton-X 100, $100 \mathrm{mM}$ Tris, $\mathrm{pH}$ 7.4, containing $100 \mathrm{mM}$ sodium pyrophosphate, 100 $\mathrm{mM}$ sodium fluoride, $10 \mathrm{mM}$ EDTA, $10 \mathrm{mM}$ sodium vanadate, $2 \mathrm{mM}$ PMSF, and $0.1 \mathrm{mg}$ of aprotinin $/ \mathrm{mL}$ ) at $4^{\circ} \mathrm{C}$ with a Polytron MR 2100 (Kinematica, Switzerland). The extracts were centrifuged at $11000 \mathrm{rpm}$ and $4^{\circ} \mathrm{C}$ in an Eppendorf 5804R (Eppendorf AG, Hamburg, Germany) for 40 min to remove insoluble material, and the supernatants of this tissue were used for protein quantification, according to the Bradford method [24]. Proteins were denaturated by boiling in Laemmli [25] sample buffer containing $100 \mathrm{mM}$ DTT, run on SDSPAGE, transferred to nitrocellulose membranes. Membranes were blocked, probed, and developed. Antibodies used for immunoblotting were anti-TNF- $\alpha$, anti-IL-1 $\beta$ (Santa Cruz Biotechnology, Santa Cruz, CA, USA). Chemiluminescence detection was performed with horseradish peroxidase-conjugate secondary antibodies. Autoradiographs of membranes were taken for visualization of protein bands. The results of blots are presented as direct comparisons of bands in autoradiographs and quantified by densitometry using the Scion Image software.

\section{Protein determination}

The amount of protein in the samples tested for TBARS, protein carbonyl and enzymes activities were determined using the Lowry technique [26]. 


\section{Statistical analysis}

Data were analyzed by one-way analysis of variance (ANOVA) followed by Tukey's test when p-values were significant $(\mathrm{p}<0.050)$. All analyses were performed using the Statistical Package for the Social Science (SPSS, v 17.0; IBM Corp, Armonk, NY) software.

\section{Results}

\section{Superoxide anion production}

The group of rats with muscle injury and no treatment had a significant increase in relation to the sham group $(\mathrm{p}=0.043)$, and only the TPU + DMSO + GNP gel group showed a significant decrease compared to the muscle injured without treatment group $(\mathrm{p}=0.023)$ (Figure 1).

\section{Lipid peroxidation and protein carbonyls}

The levels of lipid peroxidation of the groups of rats with muscle injury and no treatment group $(\mathrm{p}=0.007)$ and the DMSO gel group $(\mathrm{p}=0.007)$ presented a significant increase compared to the sham group. Similarly, the GNP gel $(\mathrm{p}=0.025)$, TPU + GNP gel $(\mathrm{p}=0.023)$, and TPU + DMSO + GNP gel $(\mathrm{p}=0.013)$ groups presented a significant decrease when compared to the muscle injury group without treatment (Figure 2A). Protein carbonylation was also significantly higher in the muscle injury group without treatment when compared to the sham group $(\mathrm{p}=0.017)$. The GNP gel $(\mathrm{p}=$ $0.020)$, DMSO + GNP gel $(\mathrm{p}=0.035)$, and TPU + DMSO gel $(p=0.010)$ groups showed a significant decrease compared to the muscle injury group without treatment (Figure 2B).

\section{Superoxide dismutase, glutathione peroxidase and catalase activities}

When analyzing superoxide dismutase activity, the muscle injury without treatment $(\mathrm{p}=0.001)$ and GNP gel $(\mathrm{p}=$ $0.006)$ groups presented a significant increase in relation to the sham group. The DMSO gel $(p=0.001)$, DMSO +
GNP gel $(p=0.013)$, TPU $(p=0.003)$, TPU + DMSO gel $(\mathrm{p}=0.001), \mathrm{TPU}+\mathrm{GNP}$ gel $(\mathrm{p}=0.001)$, and TPU + $\mathrm{DMSO}+\mathrm{GNP}$ gel $(\mathrm{p}=0.001)$ groups showed a significant decrease in relation to the muscle injury without treatment (Figure 3A).

With regard to glutathione peroxidase activity, the muscle injury without treatment group $(\mathrm{p}=0.035)$ had a significant increase in relation to the sham group, and only the TPU + DMSO + GNP gel $(\mathrm{p}=0.021)$ group showed a significant decrease in relation to the muscle injury without treatment group (Figure 3B).

As for catalase activity, the muscle injury without treatment $(\mathrm{p}=0.002)$ and GNP gel $(\mathrm{p}=0.017)$ groups showed a significant increase in relation to the sham group. Similarly, the TPU + DMSO gel ( $p=0.008)$, $\mathrm{TPU}+\mathrm{GNP}$ gel $(\mathrm{p}=0.008)$, and TPU + DMSO + GNP gel $(p=0.002)$ groups showed a significant decrease in relation to the muscle injury without treatment (Figure 3C).

\section{Pro-inflammatory Cytokines}

With regard to TNF- $\alpha$ levels, the muscle injury without treatment $(\mathrm{p}=0.000)$ DMSO gel $(\mathrm{p}=0.001)$ and TPU $(\mathrm{P}=0.000)$ groups had a significant increase in relation to the sham group. The GNP gel $(\mathrm{p}=0.040), \mathrm{DMSO}+$ GNP gel $(p=0.035)$, TPU + DMSO gel $(p=0.035)$ groups presented a significant decrease in the levels of TNF- $\alpha$ in relation to the muscle injury without treatment group. The TPU + GNP gel and TPU + DMSO + GNP gel groups showed a significant decrease compared to all other groups except sham (Figure 4A).

We also evaluate IL-1 $\beta$ levels and here the muscle injury without treatment $(\mathrm{p}=0.000)$ and DMSO gel $(\mathrm{p}=0.000)$ groups showed a significant increase compared to the sham group. Similarly, the GNP gel $(\mathrm{p}=0.025)$, DMSO + GNP gel $(p=0.016)$, TPU $(p=0.020)$, and TPU + DMSO gel $(p=0.011)$ groups showed a significant decrease compared to the muscle injury without treatment group. On the other hand, the TPU + GNP gel and TPU + DMSO +
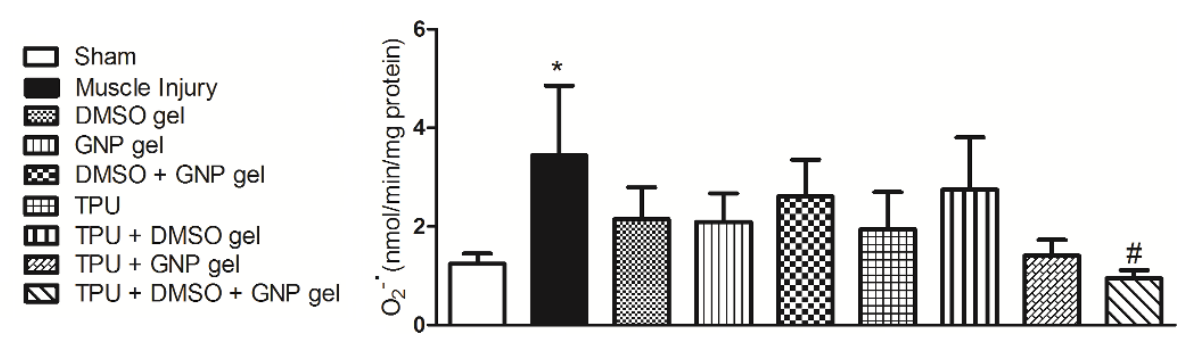

Figure 1 Effect of therapeutic pulsed ultrasound (TPU) + DMSO + GNP gel on anion superoxide production in skeletal muscle after injury (seven days). Data are expressed as mean \pm SEM for six animals. Different from sham $\left({ }^{*} p<0.050\right)$ and different from muscle injury without treatment ( $\left.{ }^{\#} p<0.050\right)$. (Tukey's test). 


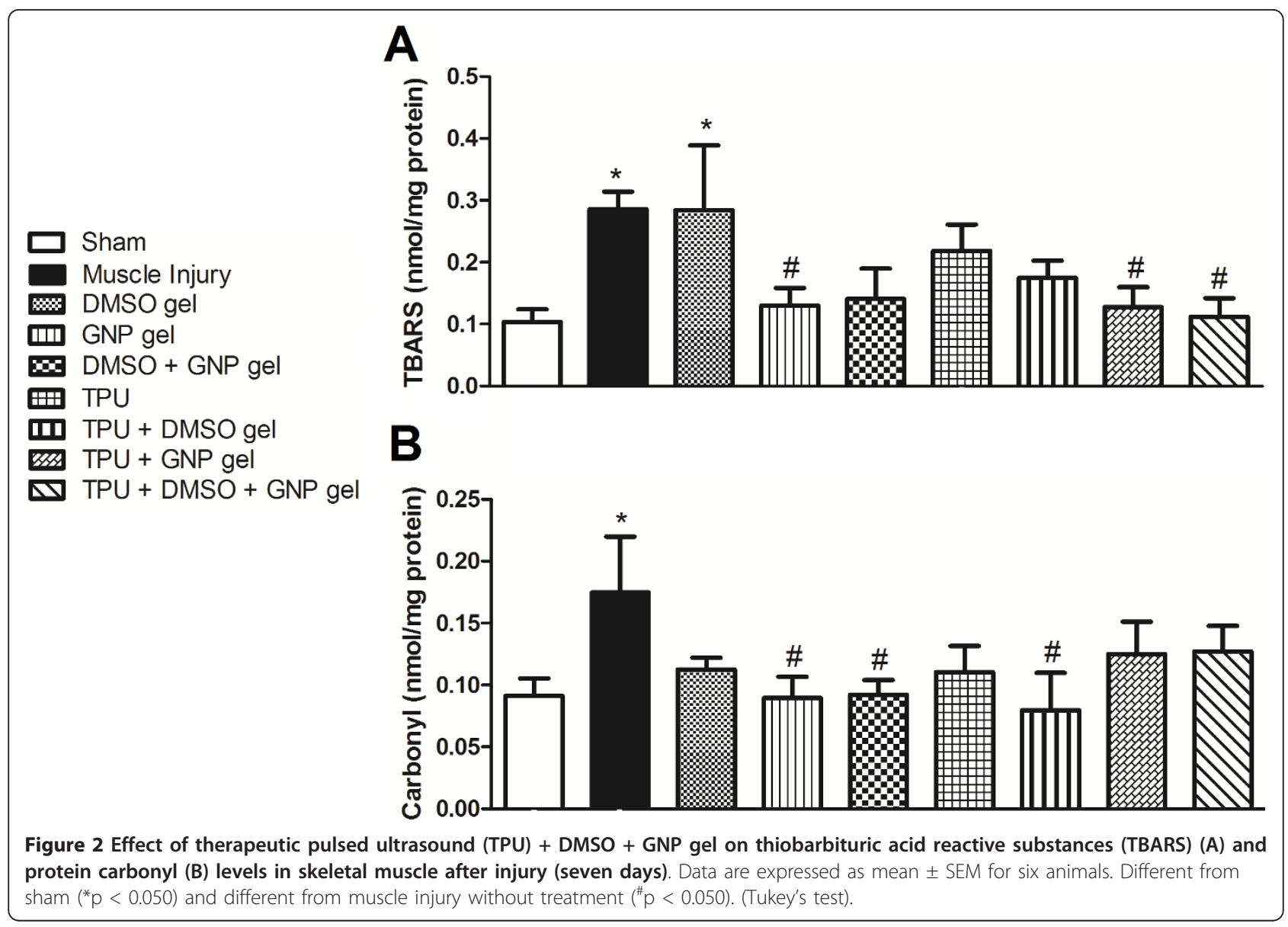

GNP gel groups showed a significant decrease compared to all other groups except sham (Figure 4B).

\section{Discussion}

Studies conducted over the past 15 years show that reactive oxidative species (superoxide, hydroxyl radicals, nitric oxide, peroxynitrite, and the free radical-derived product hydrogen peroxide) play an important role in inflammation and or infection-induced alterations in muscle function [27]. In the present study, we induced a traumatic muscle injury and assessed oxidative stress parameters after seven days. Figures 1, 2 and 3 show that there was an increase in superoxide anion production, TBARS levels, and carbonyl content, as well as in the activity of the antioxidant enzymes SOD, GPX and $\mathrm{CAT}$ in the muscle lesion group when compared to the sham.

After initial muscle injury, oxidative stress might have increased due to a number of potential sites for the generation of ROS within the traumatized muscle [28]. Primary sources of free radicals may include mitochondria, xanthine oxidase enzymes (XO), prostanoid metabolism, and $\mathrm{NAD}(\mathrm{P}) \mathrm{H}$ oxidases [29]. Reactive oxidative species are potent oxidizing and reducing agents which cause cell membrane damage by lipid peroxidation and also induce damage to proteins by neutrophil activation [30]. Cell injury activates cyclooxygenase and lipoxygenase pathways along with transition metal ions, which increase lipid peroxidation and protein carbonylation in the surrounding tissues [31].

However, in our treatment groups, only the TPU + DMSO + GNP gel group showed a significant decrease in superoxide anion production and TBARS levels, and it was the only group to show a decrease in all antioxidant enzyme levels compared to the muscle injury group.

TPU by transmitting as an acoustic pressure wave and indirectly applying mechanical stress to the tissues has been reported to promote protein synthesis, calcium uptake, and DNA synthesis in different cells [32-34]. Furthermore, ultrasound may enhance penetration of anti-inflammatory agents applied onto the skin in a technique called phonophoresis due to the cavitation phenomenon, the generation of gas bubbles, which oscillate and may implode at the skin surface, thus producing disorganization and/or an aqueous pathway 


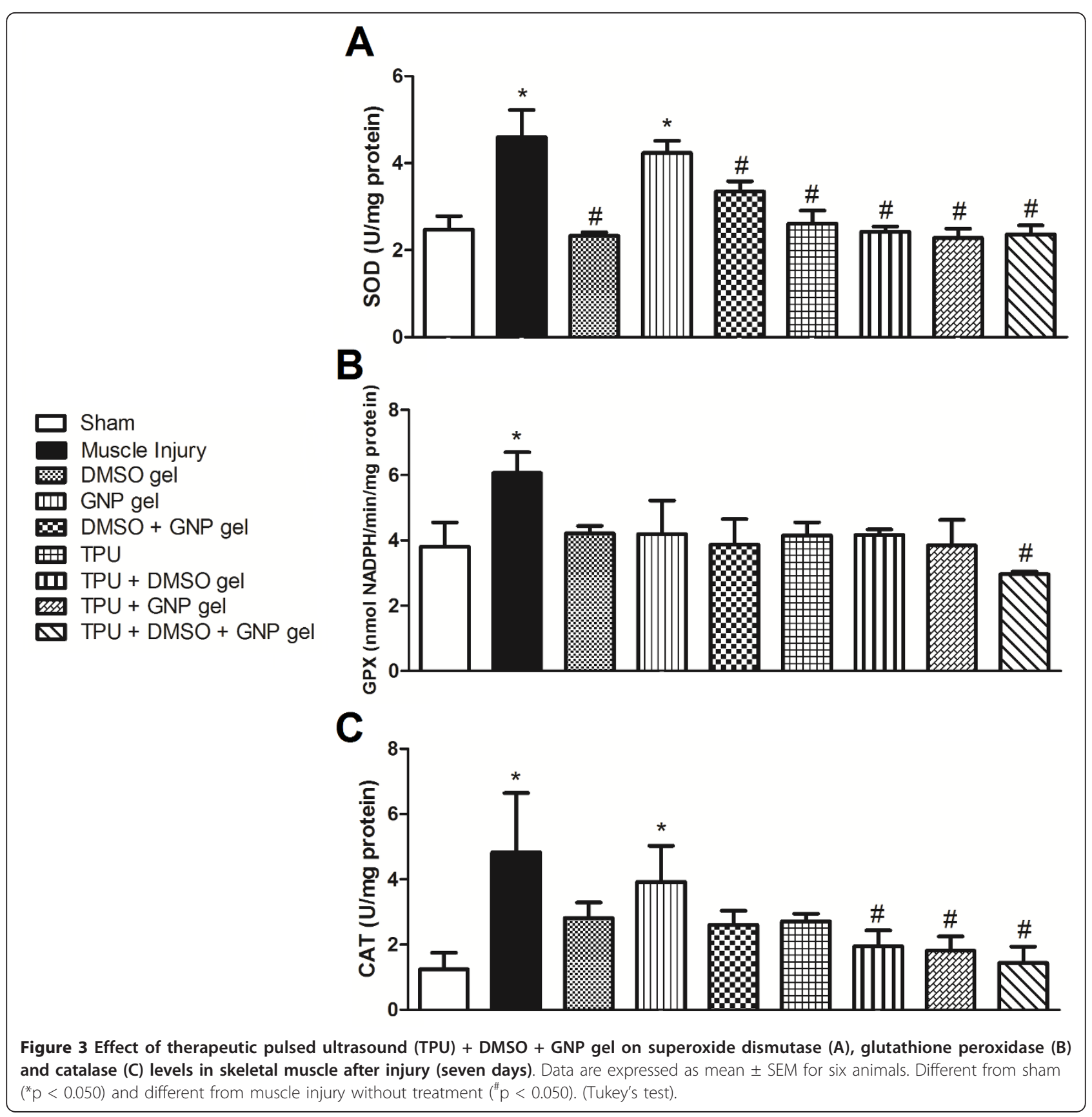

through the stratum corneum [35-37]. Taking advantage of these properties, we introduced gold nanoparticles in the conductor gel of the pulsed ultrasound, as Figures 1, 2, and 3 show, antioxidant effects were observed.

Gold preparations used in Indian medicine systems (Ayurveda, Siddha and Unani-Tibb), have been attributed various medicinal uses. The metal is widely used in modern medicine for the treatment of rheumatoid arthritis [38]. Recent studies [39-42] demonstrated that metal nanoparticles are potential antioxidants. Bimetallic nanoparticles consisting of gold and platinum are effective in quenching reactive oxidative species (ROS), including hydrogen peroxide $\left(\mathrm{H}_{2} \mathrm{O}_{2}\right)$ and the superoxide anion radical $\left(\mathrm{O}_{2}^{-*}\right)$, in dose-dependent manner and gold nanoparticles enhance the antioxidant activity of vitamin E. In addition, gold and platinum nanoparticles have been found to catalyze oxidation of NADH to NAD.

In general, we believe that the effects on oxidative stress of both therapies are improved when used 


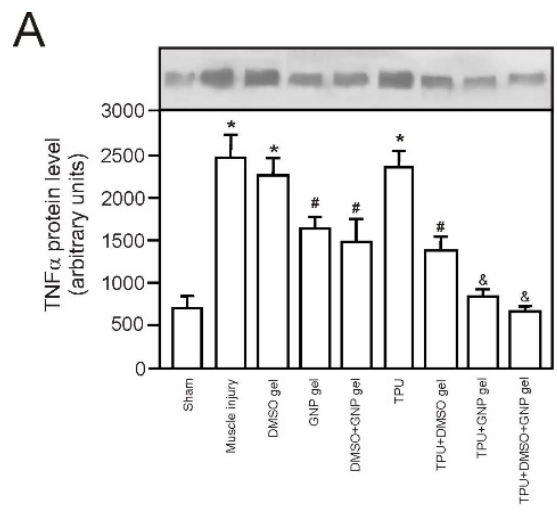

$\mathrm{IB}: \beta$-actin
B

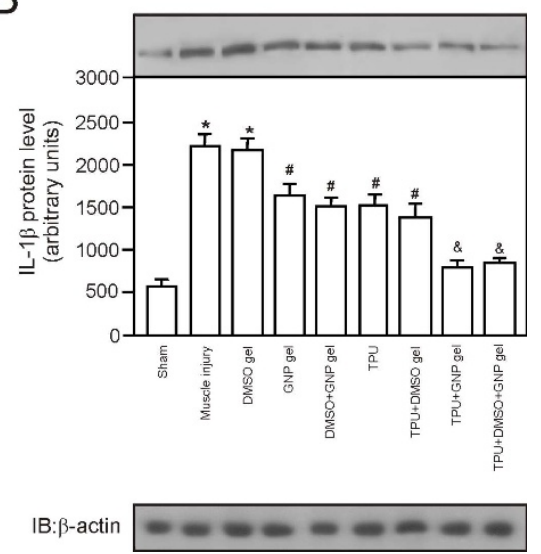

Figure 4 Effect of therapeutic pulsed ultrasound (TPU) + DMSO + GNP gel on protein levels of cytokines in skeletal muscle after injury (seven days). Protein levels of TNF- $\alpha$ (A) and IL-1 $\beta$ (B). ${ }^{*} p<0.050$ versus Sham group; ${ }^{\#} p<0.050$ versus muscle injury group; and ${ }^{\&} p<$ 0.050 versus all other groups except sham.

together. To better understand this mechanism, we have also evaluated the effects of phonophoresis with gold nanoparticles on TNF- $\alpha$ and IL- $1 \beta$ levels.

In our study, we show that the muscle lesion model increases TNF- $\alpha$ and IL- $1 \beta$ levels compared to the sham group. After muscle injury, there is a fast necrosis of the muscle fibers and activation of inflammation, which contributes to the removal of necrotic material and secretion of several cytokines and growth factors, stimulating satellite cell activation [43]. Immediately after an injury to skeletal muscle, the gap formed between the ruptured muscle fibers is filled with a hematoma, where macrophages and fibroblasts are activated, producing additional chemotactic signals (e.g. growth factors, cytokines, and chemokines) for the circulating inflammatory cells [44].

However, the DMSO gel group showed a significant increase in TNF- $\alpha$ and IL-1 $\beta$ levels compared to the muscle injury group, while the TPU + GNP gel and TPU + DMSO + GNP gel group showed a significant decrease compared to all groups except sham.

During the inflammatory phase of the healing process, ultrasound can activate immune cells to migrate to the lesion site. In two separate studies, Fyfe et al. (1982, 1984) showed ultrasonic induction $\left(0.5 \mathrm{~W} / \mathrm{cm}^{2}\right)$ of mast cell degranulation and histamine release in injury models in vivo $[45,46]$. Similar results were reported for dermal mast cells, demonstrating that ultrasound can accelerate the inflammatory healing phase for skin lesions/ulcers in vivo (Wistar rats, 0.75-3 MHz, 0.25-3 $\left.\mathrm{W} / \mathrm{cm}^{2}\right)[45,46]$.

TPU stimulate a better response to the inflammatory process; however, the TPU + GNP gel and TPU + DMSO + GNP groups showed the highest decrease in TNF- $\alpha$ and IL-1 $\beta$ levels. Ultrasound is known to facilitate molecule transit across membranes. Ultrasound stimulation may influence the activity of plasma membrane $\mathrm{Ca}^{2+}$-ATPase, $\mathrm{H}^{+}$-ATPase, and other ion channels [47]. Due to these properties, TPU can be used together with anti-inflammatory or antioxidant drugs (phonophoresis) promoting a higher absorption and potentiating their effects $[48,49]$.

Gold compounds have received great attention as anti-inflammatory agents due to their ability to inhibit expression of NF- $\kappa \mathrm{B}$ and subsequent inflammatory reactions [50,51]. Auranofin (AF; 2,3,4,6-tetra-Oacetyl-1-thio-(-D-glucopyranosato-S-[triethylphosphine] gold) is a sulfur-containing gold compound, which has been widely used for the treatment of rheumatoid arthritis [52]. It has been shown that AF has antiinflammatory and immunosuppressive activities. The drug blocks NF- $\kappa \mathrm{B}$ activation by interacting with cys179 of IKK- $\beta$ and inhibits the production of proinflammatory cytokines such as IL-1 $1 \beta$ and TNF- $\alpha$ [53]. In fact, we believe that the association between TPU and GNP promotes major changes in muscle inflammation.

\section{Conclusions}

Our findings suggest that phonophoresis with gold nanoparticles has antioxidant effect and, consequently, it decreases pro-inflammatory cytokine levels. Our results show that this treatment decreases the injured tissues exposure to reactive oxidative species, thus decreasing structural damages caused by this exposure and probably hastening the acute inflammatory phase.

Thus, gold nanoparticles suggest a promising application in the recovery of muscle lesions; however, further studies are needed in order to elucidate their precise mechanism of action. 


\section{Acknowledgements}

This work was supported by grants from Conselho Nacional de Pesquisa e Desenvolvimento (CNPq), CAPES and Universidade do Extremo Sul Catarinense (UNESC). The authors would also like to thank CNPq and UNESC for fellowship support.

\section{Author details}

'Laboratory of Synthesis of Multifunctional Complexes, UNESC Av. Universitária, 1105 - Bairro Universitário Phone: + 554834312773 88806-000 - Criciúma - SC, Brazil. ${ }^{2}$ Laboratory of Physiology and Biochemistry of Exercise, UNESC Av. Universitária, 1105 - Bairro Universitário Phone: + 5548 34312773 88806-000 - Criciúma - SC, Brazil. ${ }^{3}$ Laboratory of Experimental Physiopathology, UNESC Av. Universitária, 1105 - Bairro Universitário Phone: + 554834312773 88806-000 - Criciúma - SC, Brazil.

\section{Authors' contributions}

EGV, PCLS, JCP, GLR and UBM performed all necessary experiments, EGV, PCLS, CTS, RAP, LS, ES and MMSP analyzed data and wrote manuscript. All authors read and approved the final manuscript.

\section{Competing interests}

The authors declare that they have no competing interests.

Received: 22 October 2011 Accepted: 12 March 2012

Published: 12 March 2012

\section{References}

1. Woodhouse JB, McNally EG: Ultrasound of Skeletal Muscle Injury: An Update. Semin Ultrasound CT MRI 2011, 32:91-100.

2. Tidball JG: Inflammatory processes in muscle injury and repair. Am J Physiol Regul Integr Comp Physiol 2005, 288:345-R353.

3. Saborido A, Naudí A, Portero-Otín M, Pamplona R, Megías A: Stanozolol treatment decreases the mitochondrial ROS generation and oxidative stress induced by acute exercise in rat skeletal muscle. J Appl Physiol 2011, 110(3):661-669.

4. Silva LA, Pinho CA, Silveira PCL, Tuon T, Souza CT, Dal-Pizzol F, Pinho RA: Vitamin E supplementation decreases muscular and oxidative damage but not inflammatory response induced by eccentric contraction. Physiol Sci 2010, 60:51-57.

5. Jackson MJ, Pye D, Palomero J: The production of reactive oxygen and nitrogen species by skeletal muscle. Appl Physiol 2007, 102:1664-1670.

6. Serrano AL, Baeza-Raja B, Perdiguero E, Jardı M, Muñoz-Canoves $P$ : Interleukin-6 Is an Essential Regulator of Satellite Cell-Mediated Skeletal Muscle Hypertrophy. Cell Metabolism 2008, 7:33-44.

7. Li YP: TNF-a is a mitogen in skeletal muscle. Am J Physiol Cell Physiol 2003, 285:370-376.

8. Demir H, Menku P, Kirnap M, Calis M, Ikizceli I: Comparison of the Effects of Laser, Ultrasound, and Combined LaserpUltrasound Treatments in Experimental Tendon Healing. Lasers Surg Med 2004, 35:84-89.

9. Alfredo PP, Anaruma CA, Pião $A C$, João SM, Casarotto RA: Effects of phonophoresis with Arnica montana onto acute inflammatory process in rat skeletal muscles: an experimental study. Ultrasonics 2009, 49:466-471.

10. Yang JH, Kim TY, Lee JH, Yoon SW, Yang KH, Shin SC: Anti-Hyperalgesic and Anti-Inflammatory Effects of Ketorolac Tromethamine Gel using Pulsed Ultrasound in Inflamed Rats. Arch Pharm Res 2008, 31:511-517.

11. Sokolov K, Follen M, Aaron J, Pavlova I, Malpica A, Lotan R: Real-time vital optical imaging of precancer using antiepidermal growth factor receptor antibodies conjugated to gold nanoparticles. Cancer Res 2003, 63:1999-2004.

12. Levy R, Thanh NT, Doty RC, Hussain I, Nichols RJ, Schiffrin DJ: Rational and combinatorial design of peptide capping ligands for gold nanoparticles. J Am Chem Soc 2004, 126:10076-10084.

13. Tsai $\mathrm{CH}$, Shiau $\mathrm{A}$, Chen S: Amelioration of collagen-Induced arthritis in rats by nanogold. Arthritis Rheum 2007, 56:544-554.

14. Turkevich J, Stevenson P, Hillier J: A study of the nucleation and growth processes in the synthesis of colloidal gold. Discuss Faraday Soc 1951, 11:55-60.

15. Rizzi CF, Mauriz UL, Corrêa DSF, Moreira AJ, Zettler CG, Filippin LI, Marroni NP, Saliba S, Mistry DJ, Perrin DH: Phonophoresis and the absorption of dexamethasone in the presence of an occlusive dressing. J Athl Train 2007, 42:349-354.
16. Silveira PC, Victor EG, Schefer DL, Silva LA, Streck EL, Paula MM, Pinho RA: Effects of therapeutic pulsed ultrasound and dimethylsulfoxide (DMSO) phonophoresis on parameters of oxidative stress in traumatized muscle. Ultrasound in Med \& Biol 2010, 36:44-50.

17. Saliba S, Mistry DJ, Perrin DH, Gieck J, Weltman A: Phonophoresis and the Absorption of Dexamethasone in the Presence of an Occlusive Dressing. J Athl Train 2007, 42:349-354

18. Poderoso JJ, Carreras MC, Lisdero C, Boveris A: Nitric oxide inhibits elEctron transfer and increases superoxide radical production in rat heart mitochondrial and submitochondrial particles. Archives in Biochemistry \& Biophysics 1996, 328:85-92.

19. Draper HH, Hadley M: Malondialdehyde determination as index of lipid peroxidation. Meth Enzymol 1990, 186:421-431.

20. Levine RL, Garland D, Oliver CN: Determination of carbonyl content in oxidatively modified proteins. Meth Enzymol 1990, 186:464-478.

21. Bannister JV, Calabrese L: Assays for SOD. Meth Biochem Anal 1987, 32:279-312.

22. Wendel A: Glutathione peroxidase. Methods Enzymol 1981, 77:325-333.

23. Aebi H: Catalase in vitro. Meth Enzymol 1984, 105:121-126.

24. Bradford MM: A rapid and sensitive method for the quantitation of microgram quantities of protein utilizing the principle of protein-dye binding. Anal Biochem 1976, 72:248-254.

25. Laemmli UK: Cleavage of structural proteins during the assembly of the head of bacteriophage T4. Nature 1970, 227(5259):680-685.

26. Lowry OH, Rosebough NG, Farr AL, Randall RJ: Protein measurement with the folin phenol reagent. J Biol Chem 1951, 193:265-275.

27. Supinski GS, Callahan LA: Free radical-mediated skeletal muscle dysfunction in inflammatory conditions. J Appl Physiol 2007, 102:2056-2063.

28. Bar-Shai M, Carmeli E, Ljubuncic P, Reznick AZ: Exercise and immobilization in aging animals: The involvement of oxidative stress and NF-kB activation. Free Radic Biol Med 2008, 44:202-214.

29. Halliwell B, Gutteridge JMC: Free Radical in Biology Medicine. Oxford, NY: University Press; 2007.

30. Toyokuni S: Reactive oxygen species-induced molecular damage and its application in pathology. Pathol Int 1999, 49:91-102.

31. Gillani S, Cao J, Suzuki T, Hak DJ: The effect of ischemia reperfusion injury on skeletal muscle. Injury Int I Care Injured 2011.

32. Chen YJ, Wang CJ, Yang KD, Chang PR, Huang HC, Huang YT, Sun YC, Wang FS: Pertussis toxin-sensitive Galphai protein and ERK-dependent pathways mediate ultrasound promotion of osteogenic transcription in human osteoblasts. FEBS Lett 2003, 554(1-2):154-158

33. Naruse K, Miyauchi A, Itoman M, Mikuni-Takagaki Y: Distinct anabolic response of osteoblast to low-intensity pulsed ultrasound. J Bone Miner Res 2003, 18(2):360-369.

34. Reher P, Doan N, Bradnock B, Meghii S, Harris M: Therapeutic ultrasound for osteoradionecrosis: an in vitro comparison between $1 \mathrm{MHz}$ and 45 kHz machines. Eur J Cancer 1998, 34(12):1962-1968.

35. Simonin JP: On the mechanisms of in vitro and in vivo phonophoresis. Control Rel 1995, 33:125-141.

36. Tang $H$, Wang CC, Blankschtein D, Langer R: An investigation of the role of cavitation in low-frequency ultrasound-mediated transdermal drug transport. Pharm Res 2002, 19:1160-1169.

37. Tezel A, Sens A, Mitragotri S: Investigations of the role of cavitation in low- frequency sonophoresis using acoustic spectroscopy. J Pharm Sci 2002, 91:444-453.

38. Lipsky PE: Remitive therapy in rheumatoid arthritis: clinical uses and mechanism of action. Agents and Actions 1984, 14:181-204.

39. Kajita M, Hikosaka K, litsuka M, Kanayama A, Toshima N, Miyamoto Y: Platinum nanoparticle is a useful scavenger of superoxide anion and hydrogen peroxide. Free Radic Res 2007, 41(6):615-626.

40. Nie Z, Liu KJ, Zhong CJ, Wang LF, Yang Y, Tian Q, Liu Y: Enhanced radica scavenging activity by antioxidant-functionalized gold nanoparticles: a novel inspiration for development of new artificial antioxidants. Free Radic Biol Med 2007, 43(9):1243-1254.

41. Huang X, El-Sayed IH, Yi X, El-Sayed MA: Gold nanoparticles: catalyst for the oxidation of NADH to NAD(+). J Photochem Photobiol B 2005, 81(2):76-83

42. Hikosaka K, Kim J, Kajita M, Kanayama A, Miyamoto Y: Platinum nanoparticles have an activity similar to mitochondrial NADH: ubiquinone oxidoreductase. Colloids Surf B Biointerfaces 2008, 66(2):195-200 
43. Worrell TW, Smith TL, Winegardner J: Effect of hamstring stretching on hamstring muscle performance. J Orthop Sports Phys Ther 1994, 20(3):154-159.

44. Järvinen $T A$, Järvinen $T L$, Kääriäänen $M$, Kalimo $H$, Järvinen $M$ : Muscle injuries: biology and treatment. Am J Sports Med 2005, 33(5):745-764

45. Fyfe M, Chahl L: Mast cell degranulation: a possible mechanism of action of therapeutic ultrasound. Ultrasound Med Biol 1982, 8:62-65.

46. Fyfe M, Chahl L: Mast cell degranulation and increased vascular permeability induced by 'therapeutic' ultrasound in the rat ankle joint. Br J Exp Pathol 1984, 65(6):671-676.

47. Hassan MA, Campbell $\mathrm{P}$, Kondo $\mathrm{T}$ : The role of $\mathrm{Ca}(2+)$ in ultrasoundelicited bioeffects: progress, perspectives and prospects. Drug Discov Today 2010, 15(21-22):892-906.

48. Paliwal S, Mitragotri S: Therapeutic opportunities in biological responses of ultrasound. Ultrasonics 2008, 48(4):271-278.

49. William D, O'Brien J: Ultrasound-biophysics mechanisms. Prog Biophys Mol Biol 2007, 93:212-255.

50. Norton S: A brief history of potable gold. Mol Interv 2008, 8(3):120-125.

51. Jeon Kl, Byun MS, Jue DM: Gold compound auranofin inhibits lkappa B kinase (IKK) by modifying Cys-179 of IKKbeta subunit. Exp Mol Med 2003, 35:61-66.

52. Borg G, Allander E, Lund B, Berg E, Brodin U, Pettersson H, Trang L: Auranofin improves outcome in early rheumatoid arthritis. Results from a 2-year, double blind placebo controlled study. J Rheumatol 1988, 15:1747-1754

53. Jeon Kl, Jeong JY, Jue DM: Thiol-reactive metal compounds inhibit NFkappa B activation by blocking I kappa B kinase. J Immunol 2000, 164:5981-5989.

doi:10.1186/1477-3155-10-11

Cite this article as: Victor et al:: Pulsed ultrasound associated with gold nanoparticle gel reduces oxidative stress parameters and expression of pro-inflammatory molecules in an animal model of muscle injury. Journal of Nanobiotechnology 2012 10:11.

\section{Submit your next manuscript to BioMed Central and take full advantage of:}

- Convenient online submission

- Thorough peer review

- No space constraints or color figure charges

- Immediate publication on acceptance

- Inclusion in PubMed, CAS, Scopus and Google Scholar

- Research which is freely available for redistribution

Submit your manuscript at www.biomedcentral.com/submit
Biomed Central 